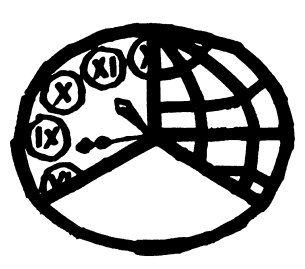

\title{
CUEVA DE LA LLUERA I (SAN JUAN DE PRIORIO, OVIEDO, ASTURIAS, ESPAÑA): ESTRATIGRAFÍA SOLUTRENSE
}

\section{La Lluera I cave (San Juan de Priorio, Oviedo, Asturias, Spain): Solutrean stratigraphy}

\author{
José Adolfo Rodríguez Asensio ${ }^{1}$, José Manuel Barrera Logares ${ }^{2}$ \\ y Eugenio Aguilar Huergo ${ }^{3}$
}

Recibido el 28 de febrero de 2013. Aceptado el 13 de septiembre de 2013

Resumen. Presentamos los niveles básicos pertenecientes al Solutrense medio y final en la cueva de La Lluera I (Asturias, España), la cual ha estado sometida a un fuerte sistema de inundaciones y vaciados que han afectado a la estratigrafía antrópica de un modo muy importante y cuyo alcance, a veces, hizo que gran parte de los niveles desaparecieran, tanto los de ocupación humana como los de sedimentación natural, reduciéndolos al mínimo en unos casos o, en otros, mezclándolos en cierta medida. Debido a ello, la estratigrafía de la cueva de La Lluera I tiene que ser interpretada desde el punto de vista sedimentológico y del análisis morfológico del río Nalón a cuya actividad han de unirse, también, los efectos de las aguas de infiltración de la ladera en cuya parte inferior se localiza la cavidad y que desde una surgencia existente en su interior desaguan al Nalón arrastrando los materiales depositados en ella.

Palabras clave: estratigrafía solutrense, cueva de La Lluera I, cuenca media del Nalón, región cantábrica, España.

Abstract. We present the basal levels belonging to the Middle Solutrean and Last Solutrean in La Lluera I cave (Asturias, Spain) that has been subjected to a strong system of floods and casts that have shaped the anthropic stratigraphy in a very important way, reaching, sometimes, to make a disappear levels, with both human occupation as natural sedimentation, minimize them or mixing them to some extent. Because it, the stratigraphy of La Lluera I cave has to be interpreted from the sedimentological and morphological analysis of the Nalón river to which activity joins, also, the upwelling of the sewer pipe of the hillside in wich lower part finds the cavity and that from inside the cave drags towards outside the materials deposited inside.

Keywords: solutrean stratigraphy, La Lluera I cave, Nalón middle basin, Cantabrian region, Spain.

\section{INTRODUCCIÓN}

La cueva de La Lluera I excavada en la década de los 80 del siglo pasado (Rodríguez Asensio 1990) e integrada en el Proyecto del Nalón Medio (Fortea 1981, 1990a; Rodríguez Asensio et al. 1989, 1990) como uno de los yaci- mientos más importantes de Europa con Arte paleolítico de grabados exteriores (Fortea 1994) ha sido, desde entonces, más analizada y citada en la literatura científica por esta circunstancia artistica (Fortea 1989, 1990b, 1994, 2001, 2005; García y Arsuaga 2003; González Echegaray y González Sáinz 1994; González Sáinz 2000, 2004; Hernando

(1) Área de Prehistoria. Departamento de Historia. Universidad de Oviedo. Calle Teniente Alfonso Martínez s/n. E-33011 Oviedo. adolfo@uniovi.es

(2) Calle Albéniz 12,2․ E-33011. Oviedo. jmebarrera@gmail.com

(3) Calle Maestro Joaquin Valdés 5, 3D. E-33930. La Felguera. e.aguilar.0@hotmail.com 
2011a, 2011b; Montes et al. 2002; Moure 1994; Ruíz 2011), sobre todo, en lo referente a su morfología, interpretación y cronología, que por su estratigrafía arqueológica y su asignación cultural.

La Lluera I se localiza en las inmediaciones de San Juan de Priorio, en el concejo de Oviedo (Asturias, España). Está situada en la margen derecha del río Nalón y tiene unas coordenadas de $43^{\circ} 19^{\prime} 53^{\prime \prime} \mathrm{N}$ y $05^{\circ} 54^{\prime} 46^{\prime \prime} \mathrm{O}$ (Datum WGS84). Su boca se abre a 5,75 m sobre el actual cauce de dicho río, teniendo una orientación Suroeste, en una unidad litoestratigráfica muy caracteristica del Carbonifero de esta zona, conocida con el nombre de calizas de Montaña. Son calizas grisáceas o gris-blanquecinas que se encuentran muy cárstificadas (Hoyos 1989) atribuidas al Namuriense.

La cueva, de reducidas dimensiones, está formada por dos galerías de entrada independientes y casi paralelas que se unen en la parte más profunda por una tercera, dando así una forma cercana al triángulo isósceles. Las dos primeras, occidental o de los grabados y oriental o de la excavación, tienen una longitud entre 16 y $18 \mathrm{~m}$, siendo de unos 10 $m$ solamente la galería de unión de ambas, transversal, de la cual salen tres galerías más estrechas y pequeñas. Dos de ellas, en la actualidad se encuentran cegadas por sedimentos, mientras que de la tercera, la más angosta y larga, sale una surgencia estacional de agua, producto fundamentalmente de las Iluvias que en la zona de dolinas superior a la cueva van filtrando hacia ésta, por la que desagua al río Nalón.

Los sedimentos de la cueva, tanto los aportados por el río en sucesivas inundaciones como los de aportación antrópica configuran una topografía interna que muestra su zona más elevada en la galería transversal, unión de las dos galerías de entrada, presentando la de los Grabados un des- nivel poco acusado hacia la boca, mientras que la galería de la excavación muestra un desnivel de $3 \mathrm{~m}$, desde la cota + 98,50 $\mathrm{m}$ sobre el nivel de mar (s.n.m.) de la entrada hasta la cota $+101,50$ m s.n.m. del fondo. La cota $+92,75$ m s.n.m. corresponde al cauce actual del río Nalón.

La cueva de la Lluera I es conocida desde antiguo por este mismo topónimo entre los habitantes de San Juan de Priorio y fue utilizada por sus dueñas como establo y abrevadero ocasional para el ganado, dado que, como ya se ha dicho anteriormente, por una de sus galerías corre una surgencia estacional de agua hoy día canalizada para evitar daños en el yacimiento. Con anterioridad, también se sabía de su uso como refugio de "fugados" en los años posteriores a la guerra civil española. Pero será en marzo de 1978 cuando su nombre comience a conocerse en el ámbito científico, ya que a raíz de las exploraciones sistemáticas que se estaban llevando a cabo en la zona central de Asturias por parte del grupo espeleológico Polifemo de Oviedo; sus miembros al visitar esta cueva se percataron de la existencia de "rayas en la pared" que parecian similares a los grabados prehistóricos que habian sido descubiertos meses antes en el abrigo de La Viña, comprobando al mismo tiempo que existian indicios de un posible yacimiento arqueológico, ya que en el surco que habia ido dejando la citada surgencia de agua en el suelo de la Galeria de los Grabados recogieron algunas lascas y útiles de factura paleolítica. Estos hechos, fueron puestos en conocimiento del Departamento de Prehistoria de la Universidad de Oviedo, dirigido por el profesor Dr. Javier Fortea Pérez.

Tras comprobarse la autenticidad de los grabados prehistóricos, así como su gran importancia (Fortea 1981), se constató que los indicios de yacimiento arqueológico también eran acertados y que en la citada cueva se con-

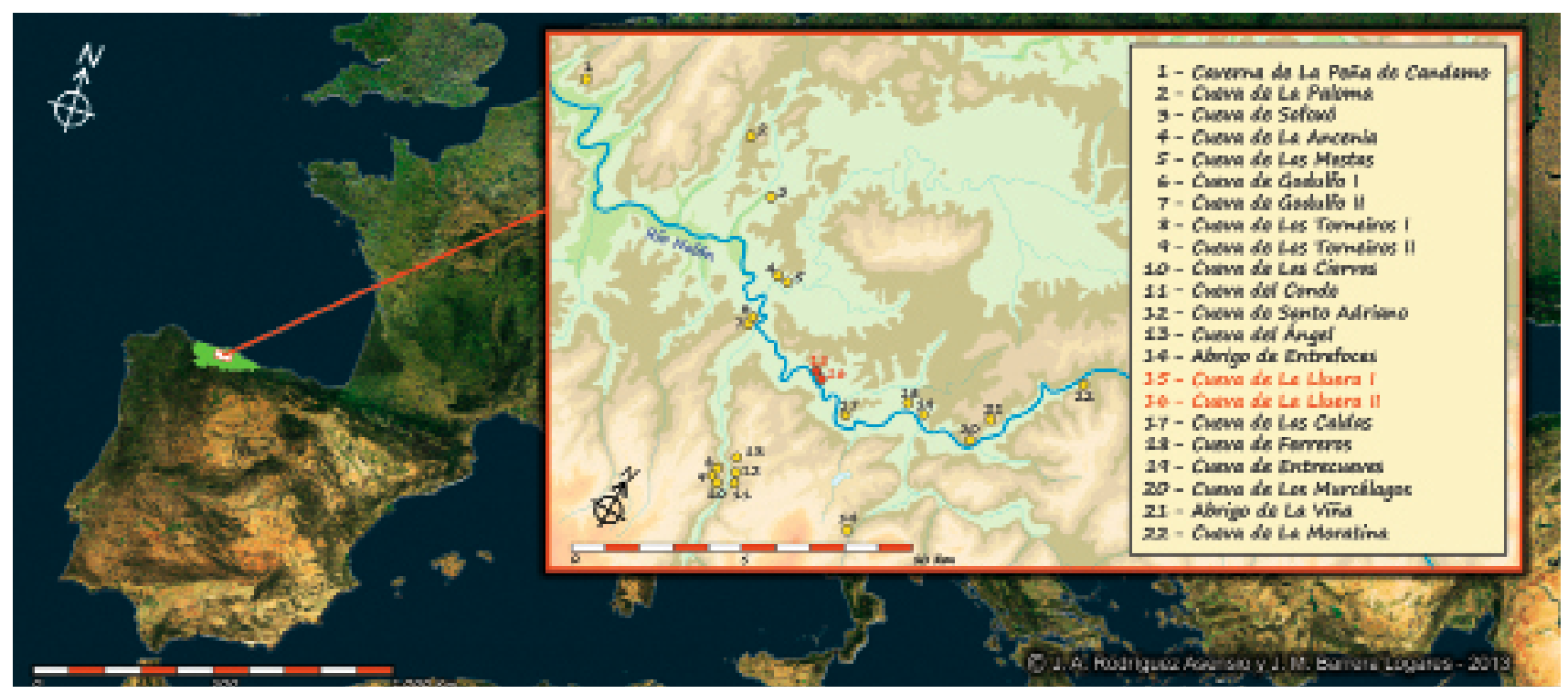

$\Delta$ Figura 1. Localización de las cuevas y abrigos con arte y/o yacimiento paleolítico de la cuenca media del río Nalón (Asturias, España). En rojo se destacan las cuevas de La Lluera. 
servaban restos que, en una primera aproximación, hacian sospechar la existencia en el lugar, a pesar de sus reducidas dimensiones, de un depósito con abundante riqueza arqueológica. Indicios que naturalmente cobraban mayor importancia al estar necesariamente ligados a los importantísimos grabados prehistóricos que poco a poco iban siendo leídos y que demostraban su carácter excepcional dentro del Arte rupestre paleolítico. De este modo la cueva de La Lluera I fue incluida en el denominado Proyecto Nalón medio, programa de estudios creado para el estudio conjunto de todas las localizaciones prehistóricas de la cuenca del Nalón, como uno de los yacimientos más importantes (Fig. 1). A partir de 1980, en que empezó a desarrollarse el citado Proyecto de Investigación, se realizaron sucesivas campañas de excavación, ligadas a las campañas de estudio de las muestras artísticas, hasta 1988 en que se dieron por finalizados los trabajos en el mencionado yacimiento (Fig. 2).

El planteamiento de las excavaciones arqueológicas obedeció en todo momento al interés de establecer esta posible conexión estratigráfico-cultural con las diferentes muestras de Arte paleolítico encontradas en la cueva y al mismo tiempo intentar relacionar la estratigrafía arqueológica con las ya conocidas en el mismo entorno geográfico, como es el caso de la cueva de Las Caldas (Piñera, Oviedo, Asturias) que, aunque se integró en el mismo Proyecto Nalón medio a partir de 1980, ya había sido objeto de excava- ciones anteriormente (Corchón 1981, 1990), y por tanto ya era conocida tanto su estratigrafía como su riqueza arqueológica, de manera fundamental en lo referido a la cultura solutrense.

\section{SECUENCIA ESTRATIGRÁFICA DE LA CUEVA DE LA LLUERA I}

Únicamente en el sentido de mostrar la disposición cultural que servirá de guía a nuestra descripción y estudio de los niveles solutrenses de la cueva de La Lluera I, señalaremos aquí sintéticamente la serie completa obtenida en las excavaciones de la galería oriental o de la excavación, de techo a muro:

- Estrato I. Nivel de ocupación, Aziliense. Presente en los cuadros H-8, H-9, G-10 y H-10.

- Estrato Ila. Nivel de ocupación, Aziliense. Presente en los cuadros H-8, H-9, G-10, H-10, G-11 y H-11.

- Estrato Ilb. Nivel de relleno de un paleocauce activo durante la formación del Estrato lla. Presente en los cuadros G-10, H-10, G-11, H-11, G-12 y H-13.

- Estrato Illa. Nivel estéril de limos de inundación posterior al momento de ocupación del Estrato IV. Presente en los cuadros H-8, H-9, G-10, H-10, G-11, $\mathrm{H}-11$ y G-12.

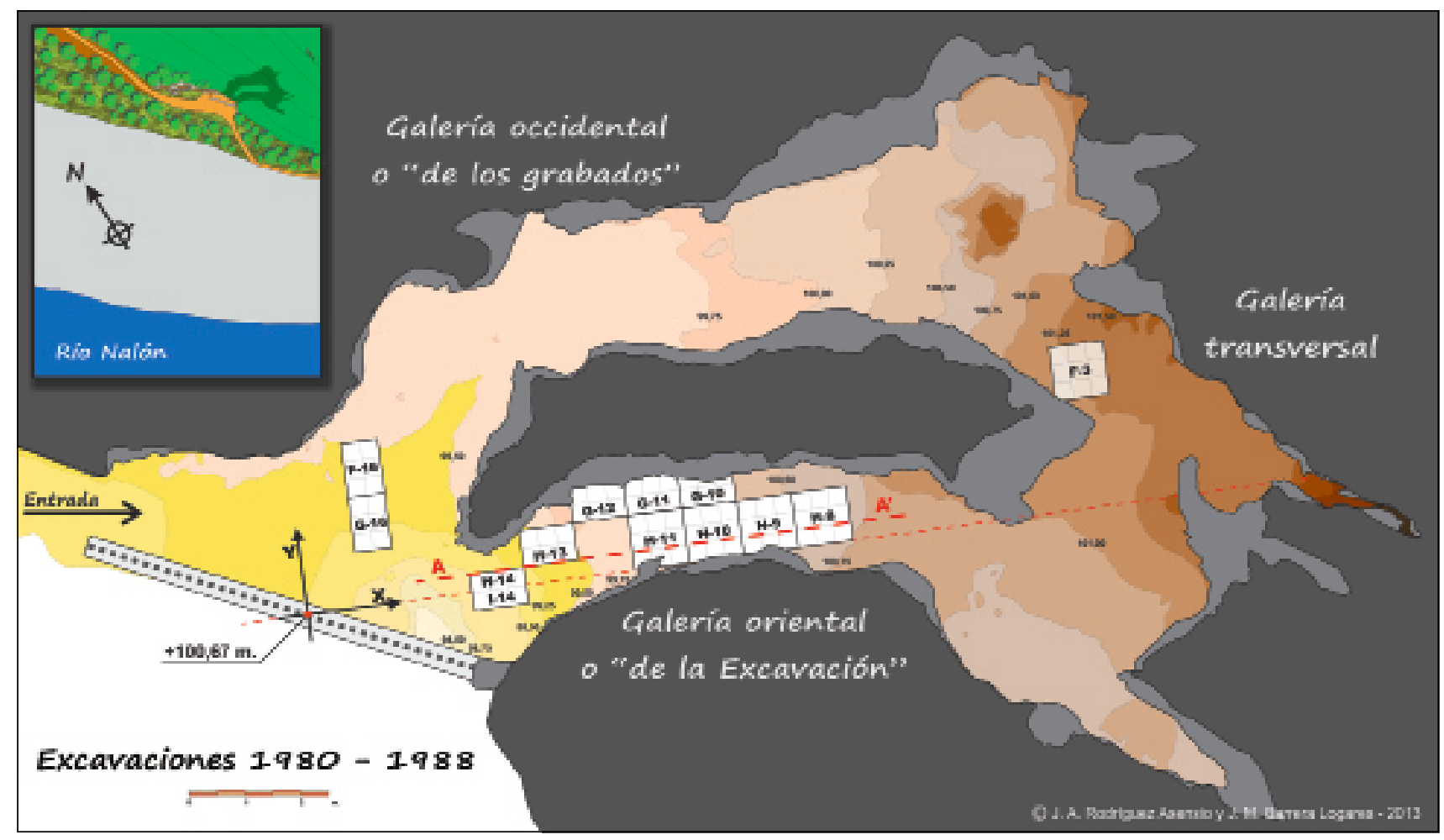

A Figura 2. Planta de la cueva de La Lluera I con indicación de las zonas excavadas. El eje A-A' (en rojo) corresponde al corte sobre el que se describe la estratigrafía de la galería oriental o "de la excavación" (Figura 4). En el recuadro, ubicación de la cueva respecto al curso actual de río Nalón. 
- Estrato Illb. Nivel estéril de limos de inundación posterior al momento de ocupación del Estrato Ila y de relleno del Ilb. Presente en G-11, H-11, G-12, $\mathrm{H}-13, \mathrm{H}-14$ e I-14.

- Estrato IV. Nivel de ocupación, Magdaleniense superior. Presente en los cuadros H-8, H-9, G-10, H-10, G-11 y H-11.

- Estrato V. Nivel estéril de limos de inundación. Presente en los cuadros H-9, G-10, H-10, G-11 y H-11.

- Estrato VI. Nivel de ocupación, Solutrense superior/ superior terminal. Presente en los cuadros $\mathrm{H}-8, \mathrm{H}-9$, G-10, H-10, G-11, H-11, G-12, H-13, H-14 e I-14.

- Estrato VII. Nivel de ocupación, Solutrense superior. Presente en los cuadros H-8, H-9, G-10, H-10, G-11 y $\mathrm{H}-11$.

- Estrato VIII. Nivel de ocupación, Solutrense medio final. Presente en los cuadros H-8, H-9, G-10, H-10, G-11 y $\mathrm{H}-11$.

- Estrato IXa. Nivel de limos de inundación con presencia testimonial de dos momentos de ocupación, Solutrense medio, una a techo y otra en base. Presente en los cuadros H-8, H-9, G-10, H-10, G-11, H-11, G-12, H-13, H-14 e I-14.

- Estrato IXb. Cubeta de remoción moderna. Presente en los cuadros $\mathrm{H}-14$ e I-14.

- Estrato X. En la base y rellenando los intersticios del suelo natural de la cueva, se verifican los restos de la terraza fluvial de $+5 \mathrm{~m}$ sobre el nivel actual del río (Rodríguez Asensio 1990; Hoyos 1994, 1995).

Visto lo cual se ha tomado como secuencia modelo la serie del cuadro $\mathrm{H}-9$, por ser la más completa e intacta, en contraposición a otros cuadros $y$, en especial, a los niveles VII y VII, que se hallan parcialmente desmontados en la entrada de la cueva por la dinámica fluvial del río Nalón. Además, como hemos observado, en esta misma zona se han individualizado algunos fenómenos erosivos, tales como los restos del paleocauce (Ilb) que discurrió desde el interior de la galería hacia afuera, de dirección noroeste-suroeste y que desmontó en fuerte escalonado parte de los Estratos VI, V, IV y IIla en los cuadros H-10, H-11, G-12 y H-13, y la presencia de una remoción en cubeta del terreno (IXb) con una acusada mezcla de sedimentos y materiales prehistóricos y modernos en los cuadros $\mathrm{H}-11$ e $\mathrm{I}-11$, factiblemente causada durante el uso de la cueva como refugio en los años posteriores a la guerra civil española.

\section{LA SERIE SOLUTRENSE}

Presentamos en esta ocasión el estudio de los niveles solutrenses definidos en las excavaciones arqueológicas que forman la parte basal de la secuencia estratigráfica y sobre los cuales se asientan niveles magdalenienses y azilienses (Rodríguez Asensio 1990).

\subsection{Estrato X}

Es el nivel más profundo y reposa directamente sobre el fondo de roca de la cueva donde se localizan, integrados en sus intersticios, los retazos de la terraza fluvial del río Nalón de $+5 \mathrm{~m}$ que obstruyó la cueva y dejó sus depósitos en los momentos finales del Würm III/IV, a tenor de lo observado en la estratigrafía de la cueva de La Lluera II (Rodríguez Asensio et al. 2012; Hoyos 1994, 1995) que se encuentra en una cota de $+1 \mathrm{~m}$ más alta que la Lluera I y en la que también se localizan, a base, los restos de esta misma terraza fluvial. Episodio de gran potencia que mantenía anegadas y taponadas por completo ambas oquedades. Esta terraza fluvial de finales del Würm III/ IV (Laugerie) que Hoyos $(1994,1995)$ define para el área cantábrica como una fase húmeda y con pulsaciones muy húmedas y de clima fresco, fue desmantelada en los últimos momentos de esta fase climática por sucesivos, y de diferentes intensidades, episodios de inundación del río, quedando únicamente los retazos mencionados sobre los que se irán configurando los diferentes momentos de ocupación antrópica.

\subsection{Estrato IXa}

Conformado por una serie de subniveles definidos por distintas tonalidades de limos finos de inundación, es un estrato de gran potencia (60 cm aprox.) en el que se registran, intercalados, dos momentos de ocupación humana; uno en su base y otro casi a techo, que se caracterizan como testimoniales arqueológicamente hablando.

Conviene señalar que este nivel sólo se ha excavado completo en los cuadros $\mathrm{H}-9, \mathrm{H}-13$ y $\mathrm{I}-14$, proporcionando indicios de las primeras ocupaciones de la cueva, restos que encuadramos en el Solutrense medio, poniéndolos en relación directa con los niveles 18 (sala 1) y 17 a 15 (pasillo) de la cercana cueva de Las Caldas, asignados al mismo período cultural (Corchón 1981).

Será pues, durante los últimos momentos del Würm III/IV (Laugerie) y los primeros del Cantábrico I (Dryas antiguo) cuando la cueva ofrezca por primera vez condiciones de habitabilidad (Hoyos 1994, 1995), siendo ya a partir de entonces objeto de diferentes ocupaciones humanas, las cuales han llegado a nosotros en diferente estado dependiendo de la zona de la cueva que se analice. Téngase presente que La Lluera I se encuentra a una cota de $+3,96 \mathrm{~m}$ sobre la terraza de inundación actual del río Nalón, lo que ha ocasionado un sistema de inundaciones y vaciados alternos de la cueva en diferentes momentos, permitiendo o impidiendo el asentamiento humano de dicha oquedad (Fig. 3). Esta circuns- 


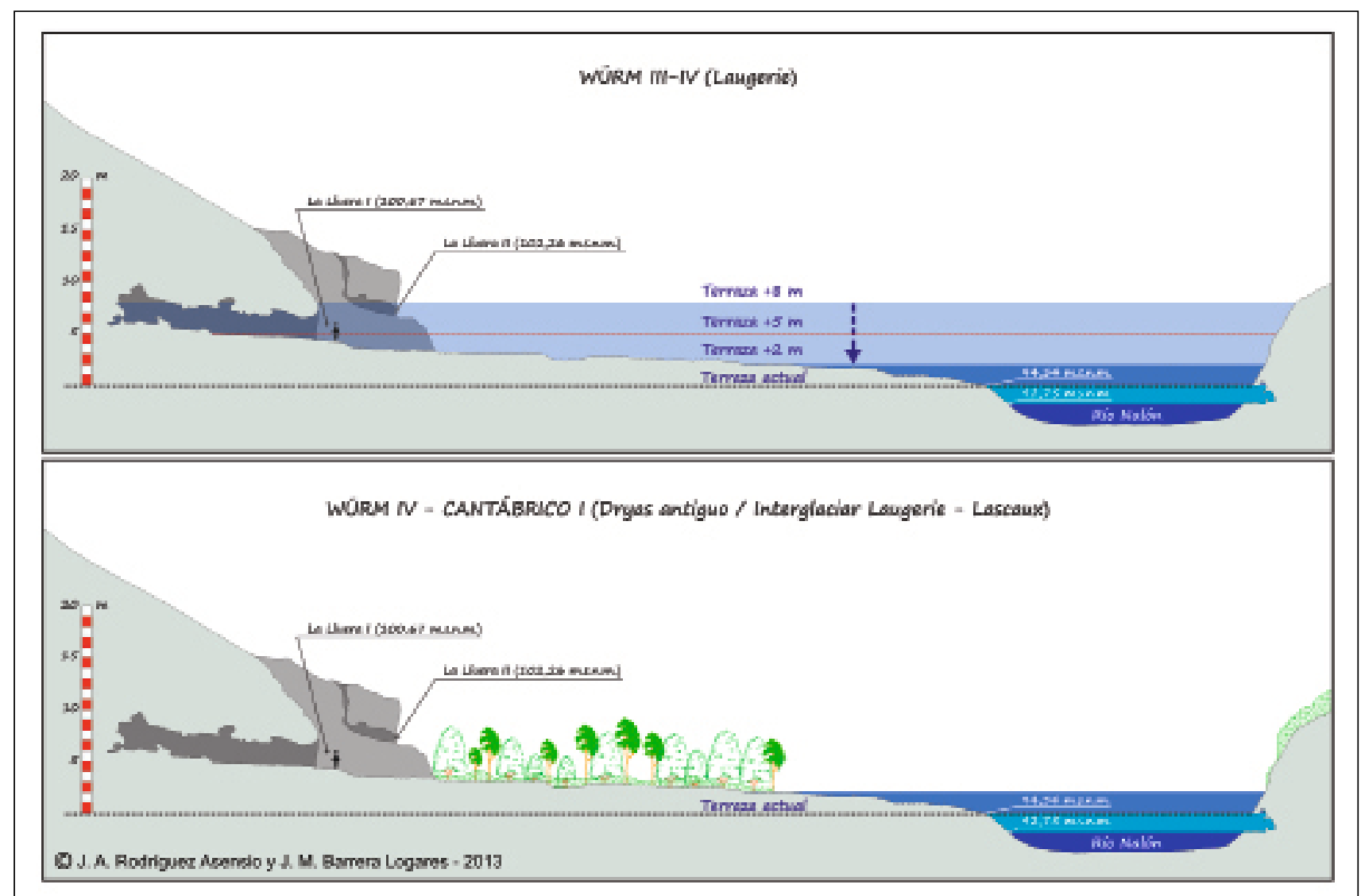

A Figura 3. Evolución de los niveles de terraza en la zona del río Nalón donde se encuentran las cuevas de La Lluera durante el Würm III-IV según M. Hoyos (1995). Será a partir del desmantelamiento de la terraza + $5 \mathrm{~m}$ cuando se produjo el vaciado de La Lluera I y, ya durante el Cantábrico I, se dieran las condiciones de no intrusión fluvial que posibilitaron su habitabilidad.

tancia le da un papel preponderante al río en la formación de la estratigrafía y explica la diferencia existente entre los niveles y, en su caso, de la potencia de los mismos al fondo de la cueva donde se conservan todos los niveles de asentamiento frente a la zona de la entrada donde algunos de ellos han sido desmantelados o presentan pequeños y muy finos restos (Fig. 4).

Hemos diferenciado, dentro de este período solutrense, los cuatro siguientes niveles hacia techo (XIa, VIII, VII y VI) que, en términos generales (Fig. 5), coinciden con las fases húmeda fría, menos húmeda de frío intenso y húmeda fría que define Hoyos $(1994,1995)$ y que según nuestro análisis arqueológico asignamos al Solutrense medio el IXa, al Solutrense medio final el VIII y ya al Solutrense superior y superior terminal el VII y el VI, aunque existen diferencias entre ellos, desde el punto de vista estratigráfico, que nos hace pensar en dos momentos de ocupación de la cueva durante el mismo período cultural y cuya correspondencia con la cueva de Las Caldas estaría en los niveles 7 y 6 (Corchón 1981). La sedimentología, estudiada por M. Hoyos (1994, 1995) también refuerza la idea de estos dos momentos diferentes de ocupación Solutrense superior.

La industria que aparece en este estrato IXa no resulta definitoria, debido a la ausencia de tipos característicos, sin embargo podemos inscribirla, como ya hemos apuntado, dentro del Solutrense medio por afinidad sedimentológica (Hoyos 1994, 1995) con los niveles 18 (sala 1) y 17 a 15 (pasillo) de la cueva de Las Caldas (Corchón 1981). Se manifiesta en dos momentos de ocupación. El primero a base, dispuesto directamente sobre los restos de la terraza de $+5 \mathrm{~m}$. Se trata de un pequeño conjunto de 28 piezas compuestas por 1 núcleo y 4 restos de núcleo en cuarcita y 7 lascas de pequeño formato del mismo material, y 16 lascas, también de pequeño formato, en sílex. El segundo momento de ocupación se verifica $50 \mathrm{~cm}$ más arriba, tras una potente secuencia de intrusiones sucesivas de limos de inundación, estando compuesto su registro por un conjunto más numeroso y variado de piezas entre las que hemos de destacar 2 buriles diedros, 3 piezas con retoque continuo marcadamente solutrense, 1 hojita de dorso y 1 hojita de sierra, todas en sílex, y un conjunto importante de restos de talla, tanto en cuarcita como en sílex, todo en pequeño formato a los que hemos de añadir la presencia de 3 restos de mineral rojizo y algunos restos óseos, aunque muy deteriorados e irreconocibles. Con posterioridad a este momento ocupacional se verifica un nuevo ciclo de intrusión de limos de inundación, esta vez de unos $10 \mathrm{~cm}$ que conforma el techo de este estrato. 


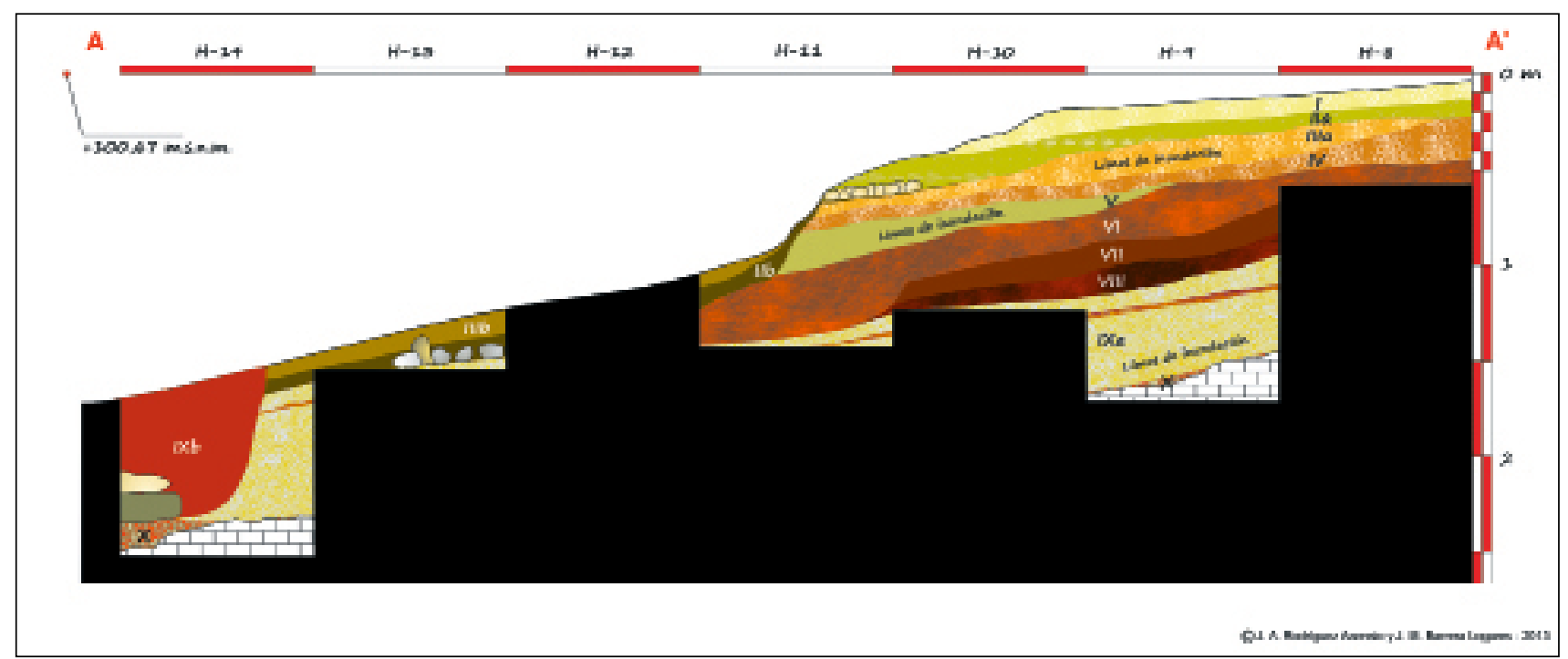

৯ Figura 4. Serie estratigráfica completa de la galería oriental o de la excavación de la cueva de La Lluera I conforme al corte A-A'.

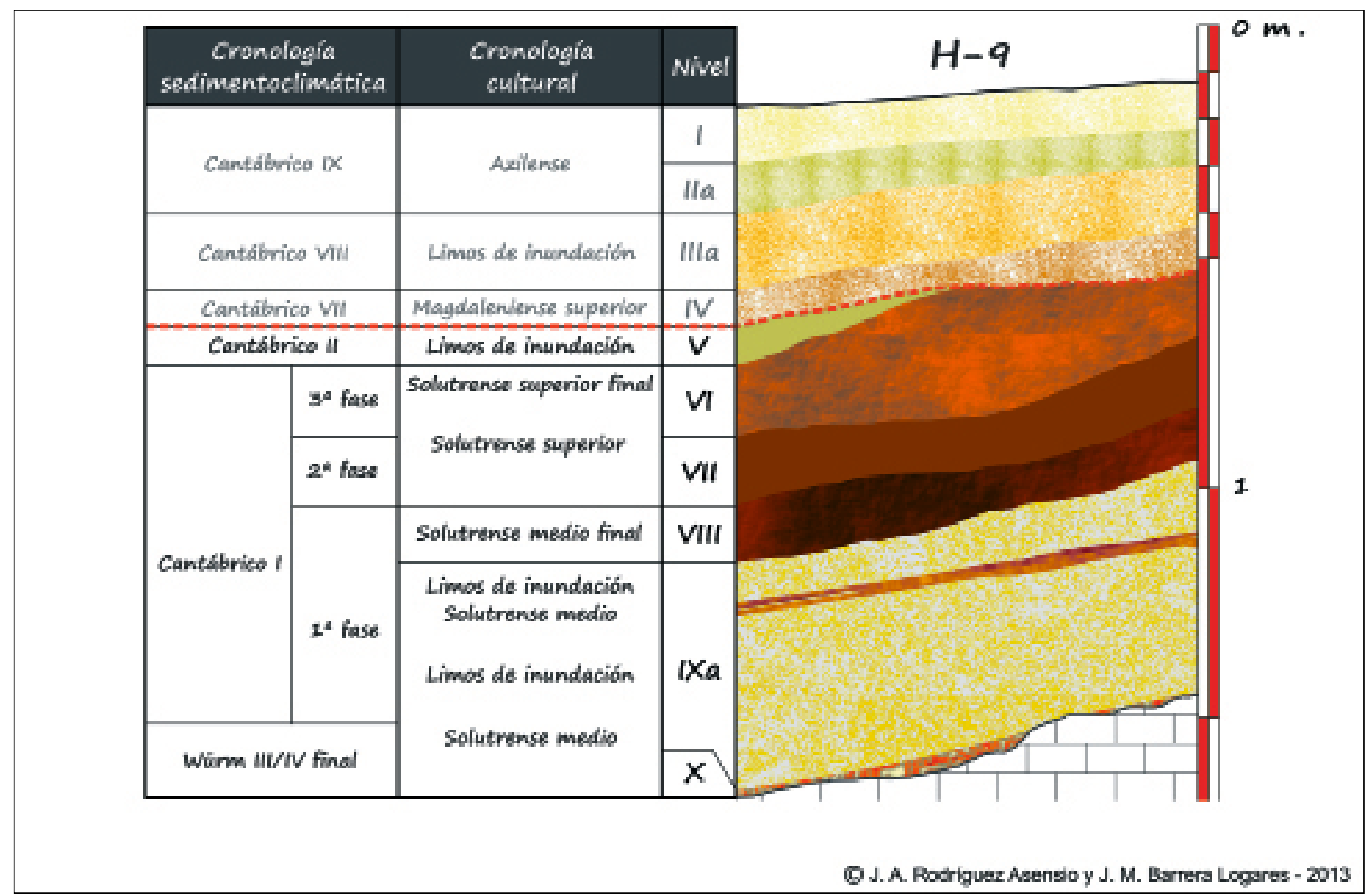

$\Delta$ Figura 5. Secuencia estratigráfica completa del cuadro H-9 (galería oriental o de la excavación) correlacionada con la cronología sedimentoclimática elaborada para el Tardiglaciar cantábrico por M. Hoyos (1994. 1995). La línea roja discontinua marca el techo de las ocupaciones solutrenses.

\subsection{Estrato VIII}

Encuadrado en los momentos finales de la primera fase, húmeda fria, del Cantábrico I (Dryas antiguo) la sedimentación del estrato VIII se encuentra directamente relacionada con procesos de gelifracción y aportes detríticos del interior de la cueva (Hoyos 1994, 1995) lo que manifiesta que su formación está directamente relacionada con unas temperaturas más frías, rigurosas y menos húmedas que las que hemos visto en el IXa. Marca el inicio de un periodo, que tendrá su continuación en los estratos VII y VI, en que las crecidas del Nalón apenas tendrán importancia y los aportes y desmontes 


\begin{tabular}{|c|c|c|c|c|c|}
\hline & \multirow{2}{*}{ Secuencia sedimentoclimática } & \multicolumn{4}{|c|}{ Cantábrico I (Dryas antiguo) } \\
\hline & & Fase 3 & Fase 2 & & \\
\hline \multirow{2}{*}{\multicolumn{2}{|c|}{ Secuencia cultural }} & \multicolumn{4}{|c|}{ Solutrense } \\
\hline & & \multicolumn{2}{|c|}{ superior } & medio final & medio \\
\hline & Estrato & VI & VII & VIII & IXa (Techo) \\
\hline \multirow{12}{*}{ 을 } & Raspadores & 199 & 64 & 12 & 0 \\
\hline & Útiles compuestos & 32 & 7 & 3 & 0 \\
\hline & Perforadores & 10 & 3 & 1 & 0 \\
\hline & Buriles & 152 & 44 & 13 & 2 \\
\hline & Útiles de borde rebajado & 81 & 13 & 3 & 0 \\
\hline & Piezas truncadas & 2 & 1 & 1 & 0 \\
\hline & Hojas retocadas & 83 & 24 & 3 & 3 \\
\hline & Útiles solutrenses & 43 & 13 & 8 & 0 \\
\hline & Piezas variadas & 54 & 6 & 2 & 0 \\
\hline & Utillaje de hojitas & 150 & 37 & 16 & 2 \\
\hline & Diversos & 19 & 0 & 0 & 0 \\
\hline & Total de Registros & 825 & 212 & 62 & 7 \\
\hline
\end{tabular}

A Tabla 1. Utillaje lítico de los niveles solutrenses de la galería oriental o de la excavación de la cueva de La Lluera I.

por escorrentías interiores disminuirán drásticamente, sobre todo coincidiendo con los momentos máximos de frío, circunstancia que también se encuentra presente en la cueva de Las Caldas (Corchón 1981). Todo ello posibilitó una habitabilidad cada vez más permanente de la cueva, circunstancia que resulta evidente al contemplar el registro arqueológico que presenta una potencia progresivamente más cuantitativa y cualitativa que la vista en el estrato anterior.

Dentro del registro lítico (Tab. 1) nos encontramos en este estrato, de unos $10 \mathrm{~cm}$ de potencia, con una colección compuesta por 62 útiles, raspadores, buriles, utillaje de hojitas; empleándose tanto la cuarcita como el sílex, aunque en una proporción mayor a favor de este último material, y entre los que hemos de destacar ya la presencia de tres puntas de cara plana en cuarcita y cinco hojas de laurel en sílex de un formato mediano realizadas en hojas gruesas similares a las encontradas en la cueva de Las Caldas (Corchón 1981) y cuyas características tecnológicas son cercanas a bifaces de pequeño formato (Figura 6).

El conjunto de restos de talla documentados (Tab. 2), ya desde este nivel, incide claramente en los modelos de materia prima ya expuestos para los útiles y reconocidos como típicos para el Solutrense cantábrico (Rasilla 1994), dándose una preponderancia notable del sílex $(71,4 \%)$ frente a las cuarcitas $(28,4 \%)$ y la presencia, anecdótica, del cuarzo $(0,2 \%)$; aunque estos valores irán fluctuando a favor de las cuarcitas conforme avancemos hacia el Solutrense superior y final. Destaca la gran abundancia de fragmentos amorfos $(42,8 \%)$, evidencia de la rigurosa y exhaustiva metodología empleada para la recogida y documentación de los materiales arqueológicos durante las campañas de excavación y que posibilitó rescatar la práctica totalidad de los datos. Del registro de lascas, hojas y hojitas sobresale el grupo de las simples $(20,8 \%)$ frente a las de decorticado que se presentan muy escasas $(3,0 \%)$. Otra característica interesante tanto de las lascas como de las hojas de este nivel es su reducido formato así como el estar realizadas en rocas de muy buena calidad por lo que han Ilegado a nosotros conservando la frescura de sus filos y sus características tecnotipológicas. El apartado de núcleos y restos de núcleo, básicamente amorfos, también se presenta muy reducido $(0,6 \%)$ estando realizados como norma en sílex.

La industria ósea resulta inexistente, motivado esto posiblemente por la mala conservación de este material debido a la fuerte humedad que presentan los niveles basales de la estratigrafía, afectados permanentemente por filtraciones de agua. La mayoria de este material aparece muy fragmentado, dándose la presencia de unos pocos ejemplares con grabado fino lineal (cinco piezas) o con marcas de carnicería (dos piezas).

Dentro del apartado de la fauna consumida (Tab. 4) nos encontramos (Altuna 1994a) con un registro formado por 166 restos reconocibles, pertenecientes a Equus ferus $(1,2 \%)$, Capra pyrenaica (8,4\%), Rupicapra rupicapra $(28,3 \%)$ y Cervus elaphus $(62,1 \%)$.

\subsection{Estrato VII}

Se encuadra en la segunda fase, menos húmeda de frío intenso, del Cantábrico I (Dryas antiguo) con apenas diferenciación alguna en el modelo de sedimentación (Hoyos $1994,1995)$ respecto al estrato anterior salvo matices en la composición y coloración del sedimento.

El registro lítico muestra un aumento cuantitativo con una colección de 212 útiles (Tab. 1) entre los que destacan 


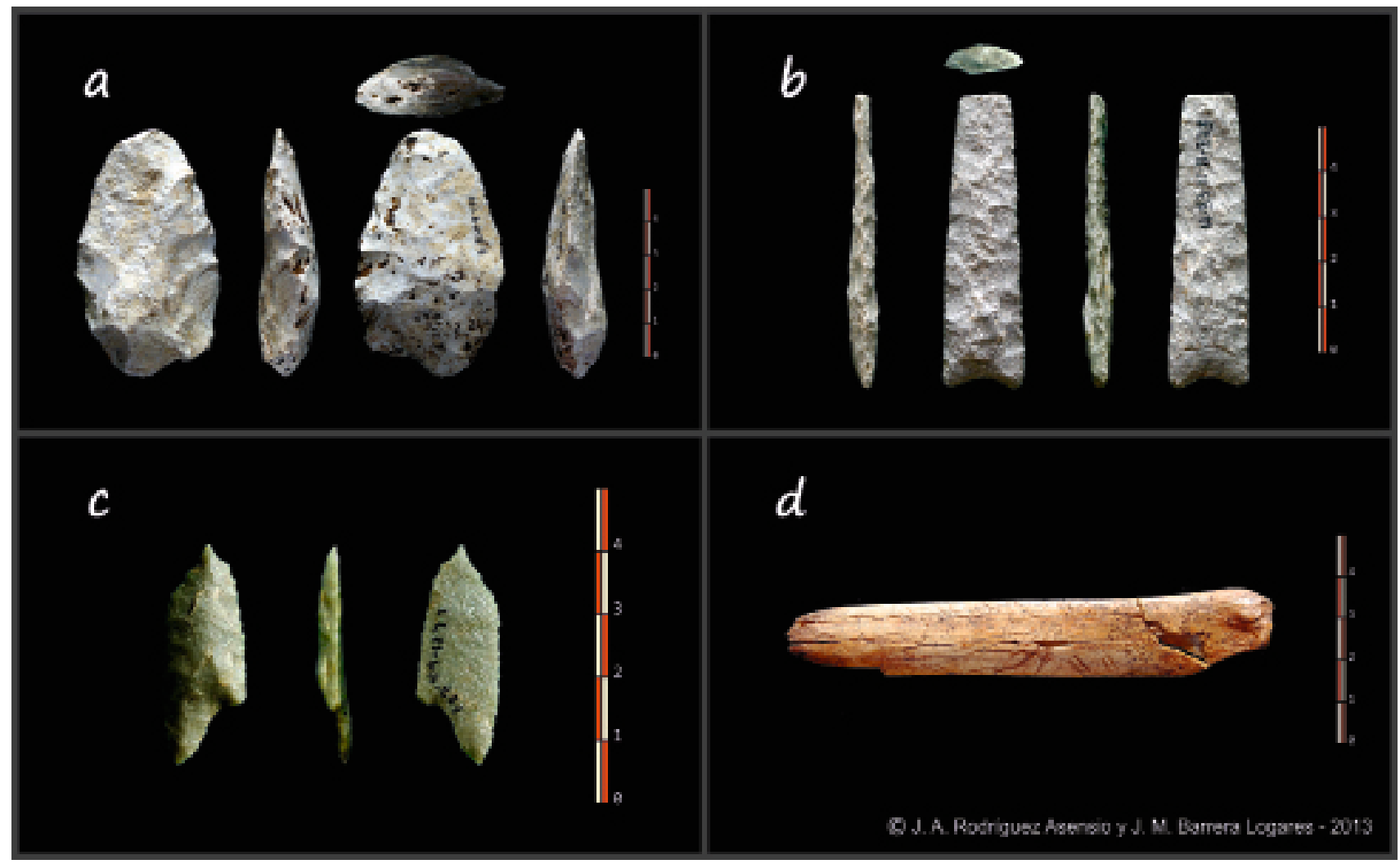

ム Figura 6. Industria de los niveles solutrenses de la cueva de La Lluera I: a, hoja de laurel del nivel VIII, Solutrense medio final; b, punta de ase Cóncava del nivel VII, Solutrense superior; c, punta de muesca del nivel VI, Solutrense superior; d, espátula grabada del nivel VI, Solutrense superior.

el grupo de los raspadores (30,19\%), los buriles $(20,75 \%)$ y el utillaje de hojitas (17,45\%). También se observa un ligero aumento en el utillaje solutrense $(11,32 \%)$ con la presencia de 8 puntas de cara plana y 5 puntas de base cóncava (Fig. 6). Característica a reseñar en este apartado es la notable diferenciación observada en el uso de la materia prima en este nivel, pudiéndose establecer una selección de la roca empleada en función del útil deseado. Así la cuarcita es mayoritaria en la elaboración de los útiles solutrenses, de los que sólo se registra uno elaborado en sílex; circunstancia francamente inversa en el resto del utillaje, como es el caso de las hojitas donde se registran 568 piezas en sílex frente a 54 en cuarcita y 10 en cuarzo.

El conjunto de restos de talla (Tab. 2) documentado en este nivel observa, como ya hemos apuntado, un ligero aumento en el uso de las cuarcitas como materia prima (32,8\%) respecto al nivel anterior, aunque el sílex continúa siendo predominante $(66,8 \%)$. Los fragmentos amorfos $(77,9 \%)$ siguen siendo los más representados y ya dentro del grupo de lascas, hojas y hojitas, las simples $(20,0 \%)$ continúan dominando sobre las de decorticado (1,2\%). El grupo de núcleos y restos de núcleo también siguen estando muy poco representado $(0,4 \%)$. Los formatos de lascas y hojas permanecen dentro de unos parámetros medianos y pequeños.

La industria ósea continúa siendo inexistente, por los motivos antes apuntados, aunque se produce un aumento notable de los fragmentos de hueso registrados al igual que de aquellos que presentan algún tipo de decoración, básicamente consistente en trazos lineales en sus diferentes variantes, horizontales, oblicuos y verticales (33 piezas) y otros con trazas claras de carniceria (7 piezas).

La fauna está presente con 353 restos reconocibles (Tab. 4) $\sin$ variaciones notables en las especies, Bos primigenius (0,3\%), Equus ferus (2,3\%), Capra pyrenaica $(20,7 \%)$, Rupicapra rupicapra $(29,2 \%)$ y Cervus elaphus $(47,5 \%)$.

Con posterioridad a la formación de este estrato y antes de que el siguiente, $\mathrm{VI}$, inicie su sedimentación se verifica una potente intrusión del río Nalón que desmontará completamente los estratos VII y VIII desde la entrada hasta los cuadros G-10 y $\mathrm{H}-10$ dejando al descubierto en toda esa zona el techo del estrato IXa y sobre el que se asentará directamente el VI, de ahí que los estratos VII y VIII sólo estén presentes integramente a partir de los citados cuadros hacia el interior de la cueva. Con ello hemos de suponer que las ocupaciones antrópicas de estos dos estratos fueron un poco más intensas que las observadas en el registro conservado.

\subsection{Estrato VI}

Con un espesor de entre 20 y $35 \mathrm{~cm}$ según zona, este es el último nivel de la serie solutrense, encuadrándose en la tercera fase, húmeda fría, final del Cantábrico I (Dryas 


\begin{tabular}{|c|c|c|c|c|c|c|c|c|c|c|}
\hline & \multirow{2}{*}{$\begin{array}{c}\text { Secuencia } \\
\text { sedimentoclimática }\end{array}$} & \multicolumn{9}{|c|}{ Cantábrico I (Dryas antiguo) } \\
\hline & & \multicolumn{3}{|c|}{ Fase 3} & \multicolumn{3}{|c|}{ Fase 2} & \multicolumn{3}{|c|}{ Fase 1} \\
\hline & \multirow{2}{*}{ Secuencia cultural } & \multicolumn{9}{|c|}{ Solutrense } \\
\hline & & \multicolumn{6}{|c|}{ superior } & \multicolumn{3}{|c|}{ medio final } \\
\hline & Estrato & \multicolumn{3}{|c|}{ VI } & \multicolumn{3}{|c|}{ VII } & \multicolumn{3}{|c|}{ VIII } \\
\hline & Material & Sílex & Cuarcita & Cuarzo & Sílex & Cuarcita & Cuarzo & Sílex & Cuarcita & Cuarzo \\
\hline \multirow{15}{*}{$\stackrel{ }{\varrho}$} & Núcleos & $0,0 \%$ & $0,0 \%$ & $0,0 \%$ & $0,0 \%$ & $0,1 \%$ & $0,0 \%$ & $0,0 \%$ & $0,0 \%$ & $0,0 \%$ \\
\hline & Restos de Núcleo & $0,3 \%$ & $0,1 \%$ & $0,0 \%$ & $0,2 \%$ & $0,1 \%$ & $0,0 \%$ & $0,4 \%$ & $0,1 \%$ & $0,0 \%$ \\
\hline & Prod. de avivado & $0,2 \%$ & $0,0 \%$ & $0,0 \%$ & $0,4 \%$ & $0,0 \%$ & $0,0 \%$ & $0,3 \%$ & $0,0 \%$ & $0,0 \%$ \\
\hline & Lascas simples & $3,1 \%$ & $3,2 \%$ & $0,0 \%$ & $4,2 \%$ & $2,9 \%$ & $0,0 \%$ & $9,3 \%$ & $3,9 \%$ & $0,0 \%$ \\
\hline & Lascas dec. primario & $0,2 \%$ & $0,2 \%$ & $0,0 \%$ & $0,1 \%$ & $0,1 \%$ & $0,0 \%$ & $0,4 \%$ & $0,5 \%$ & $0,0 \%$ \\
\hline & Lascas dec. secundario & $0,3 \%$ & $0,8 \%$ & $0,0 \%$ & $0,1 \%$ & $0,8 \%$ & $0,0 \%$ & $0,7 \%$ & $1,4 \%$ & $0,0 \%$ \\
\hline & Hojas simples & $1,1 \%$ & $0,5 \%$ & $0,0 \%$ & $1,5 \%$ & $0,3 \%$ & $0,0 \%$ & $1,7 \%$ & $0,2 \%$ & $0,0 \%$ \\
\hline & Hojas dec. primario & $0,0 \%$ & $0,0 \%$ & $0,0 \%$ & $0,0 \%$ & $0,0 \%$ & $0,0 \%$ & $0,0 \%$ & $0,0 \%$ & $0,0 \%$ \\
\hline & Hojas dec. secundario & $0,0 \%$ & $0,1 \%$ & $0,0 \%$ & $0,0 \%$ & $0,0 \%$ & $0,0 \%$ & $0,0 \%$ & $0,0 \%$ & $0,0 \%$ \\
\hline & Hojitas simples & $8,0 \%$ & $0,8 \%$ & $0,2 \%$ & $9,9 \%$ & $0,9 \%$ & $0,2 \%$ & $5,2 \%$ & $0,4 \%$ & $0,1 \%$ \\
\hline & Hojitas dec. secundario & $0,0 \%$ & $0,0 \%$ & $0,0 \%$ & $0,0 \%$ & $0,0 \%$ & $0,0 \%$ & $0,0 \%$ & $0,0 \%$ & $0,0 \%$ \\
\hline & Lascas de retoque & $0,0 \%$ & $0,0 \%$ & $0,0 \%$ & $0,0 \%$ & $0,0 \%$ & $0,0 \%$ & $10,7 \%$ & $1,0 \%$ & $0,0 \%$ \\
\hline & Fragmentos amorfos & $47,3 \%$ & $32,3 \%$ & $1,4 \%$ & $50,2 \%$ & $27,6 \%$ & $0,2 \%$ & $42,8 \%$ & $20,6 \%$ & $0,1 \%$ \\
\hline & \% Total & $60,4 \%$ & $37,9 \%$ & $1,6 \%$ & $66,8 \%$ & $32,8 \%$ & $0,4 \%$ & $71,4 \%$ & $28,4 \%$ & $0,2 \%$ \\
\hline & Total de registros & \multicolumn{3}{|c|}{17.681} & \multicolumn{3}{|c|}{5.761} & \multicolumn{3}{|c|}{3.400} \\
\hline
\end{tabular}

A TABla 2. Restos de talla de los niveles solutrenses de la galería oriental o de la excavación de la cueva de La Lluera I.

antiguo). La sedimentación de este estrato vuelve a estar relacionada con procesos de gelivación y de aportaciones detríticas internas como los que tuvieron lugar durante la formación del nivel VIII (Hoyos 1994, 1995; Rodríguez Asensio 1990) manifestando unas temperaturas frias y rigurosas, aunque más húmedas que las vistas en el nivel anterior $y_{\text {, si }}$ bien, este nivel puede entenderse dentro de la lógica evolución cultural mostrada por la serie, presenta internamente notables particularidades.

En primer lugar destaca su potencia, aunque irregular, respecto al VIII y al VII, siendo con mucho el mejor conservado desde el punto de vista arqueológico. No se ha visto tan afectado como los anteriores por las filtraciones de agua, de modo que su registro ha mantenido las características originales en gran medida, y en lo relativo a su secuencia interna presenta matices que enmarcan los diferentes momentos de ocupación. Así, hemos podido distinguir dentro del estrato al menos tres subniveles antrópicos.

El primero, a base, constituyendo un nivel de relleno y de cierta nivelación del abrupto buzamiento causado por la intrusión que desmontó los niveles VIII y VII desde la entrada hasta el inicio de los cuadros G-10 y H-10. De este subnivel basal lo más destacable es la documentación, por vez primera en la serie, de industria ósea y la evidencia de una estructura de hogar de notables proporciones a la altura del cuadro $\mathrm{H}-13$ que estaría operativa durante toda la duración de la formación del estrato, como así lo demuestran los registros arqueológicos documentados en sus inmediaciones marcadamente afectados por el fuego y presentes en cada uno de los subniveles. Culturalmente lo definimos como Solutrense superior, ya que salvo en lo referido a la industria ósea continúa dentro de los parámetros observados en el nivel VIII anterior.

El segundo subnivel, medial, más regular en su distribución a lo largo de toda la galería y mucho más potente presenta, per se, la colección arqueológica más completa de toda la serie solutrense de la cueva; no sólo en lo referido a la industria lítica u ósea, sino también en lo referido al aspecto artístico, con abundantes muestras de grabado en hueso y algunos objetos claramente describibles como de adorno personal. Culturalmente, lo entendemos como una continuación del subnivel anterior y por tanto lo adscribimos al Solutrense superior.

El tercer subnivel, ya a techo, lo asignamos al Solutrense superior final por ciertos matices observados en la industria. Su correspondencia podría establecerse con los niveles 3 y 4 de las Caldas (Corchón, 1999) quien habla de un Solutrense superior terminal. No obstante, esta asignación cronocultural presenta en nuestro caso algunos interrogantes debido, entre otros factores, al fuerte lavado en superficie a que se vio sometido durante el proceso de inundaciones del Nalón que tuvieron lugar durante los inicios de Cantábrico II (Lascaux) y que posteriormente aportaron los limos que conformaron el nivel V (Hoyos 1994, 1995). Otro factor distorsionante a la hora de analizar este subnivel es el ocasionado por la surgencia de aguas de escorrentía que desde el interior de la cueva 
buscó salida durante el momento de formación del nivel lla y lo hizo a través de esta galería. El curso de esta surgencia fue acanalándose cortando la serie estratigráfica y, ya a la altura de los cuadros $\mathrm{G}-11$ y $\mathrm{H}-11$, conformando una zona de encharcamiento que se rompió en fuerte escalón llevándose tanto el material arqueológico de este estrato como el de los niveles superiores desde ahí hasta la boca de la galería. Además, este mismo fenómeno fue el causante del intensísimo lavado sufrido por la estructura que interpretamos como hogar en el cuadro $\mathrm{H}-13$, claramente perteneciente al nivel VI y por tanto asignado al Solutrense superior.

La industria lítica documentada (Tab. 1), tanto por su número (825 útiles) como por su diversidad (48 tipos) indica sin ambages el momento máximo de ocupación solutrense de la cueva y aunque hayamos distinguido internamente varias fases, aquí lo analizaremos como un todo para facilitar la descripción de la serie solutrense, aunque hemos matizado ya algunos puntos que entendemos necesarios. El grupo más representado es el de los raspadores $(24,12 \%)$ principalmente simples en extremo de hoja, en lasca y nucleiformes; le sigue el grupo de los buriles $(18,42 \%)$ diedros rectos, diedros de ángulo y diedros múltiples; también destaca el utillaje de hojitas $(18,18 \%)$, fundamentalmente hojitas de dorso; el grupo de hojas retocadas $(10,06 \%)$ y el grupo de útiles de borde rebajado $(9,82 \%)$ como las piezas de muesca y microgravettes. El grupo solutrense $(5,21 \%)$ se encuentra representado por 21 puntas de cara plana, 9 hojas de laurel, 7 puntas de base cóncava y, claro marcador del Solutrense superior, 6 puntas de muesca de retoque plano (Fig. 6).

En lo referido a los restos de talla (Tab. 2), el registro documentado en este nivel alcanza la cantidad de 17.681 piezas, redundan claramente en la idea de que la ocupación antrópica es permanente o casi permanente en la cueva durante este momento. Hemos de hacer aquí la salvedad de que se trataría de una comunidad relativamente reducida dadas las dimensiones del lugar, de apenas unos $100 \mathrm{~m}^{2}$ habitables, lo que nos indicaría la presencia de un muy pequeño grupo de caza; sin embargo existen elementos, sobre todo la muy notable riqueza artística desarrollada en sus paredes que sitúa a ambas cuevas de La Lluera entre los más importantes santuarios paleolíticos de grabados exteriores a nivel europeo y por tanto mundial, que nos conducen a pensar en un uso más específico de estas cavidades, al menos durante este periodo, por parte de las comunidades que habitaban en toda la cuenca del río Nalón.

Continúa siendo muy escasa la presencia de núcleos y restos de núcleo $(0,5 \%)$ estando más representados los de silex $(0,4 \%)$, circunstancia que puede ser explicada por la proximidad de la terraza fluvial, apenas a unos $5 \mathrm{~m}$ de la entrada de la cueva y con gran abundancia de cantos de cuarcita, de modo que las labores de tallado en este material podrian haber sido realizadas al exterior. La escasez de bases en sílex también puede ser explicada por el pequeño formato de los nódulos disponibles y por su aprovechamiento intensivo como pude verse en la gran cantidad de industria que deriva en este tipo (buriles, raspadores, etc. nucleiformes). Las lascas simples continúan estando más representadas que las de decorticado, 6,3\% frente a un 1,5\%; sobre todo en el caso de las cuarcitas, 3,2\% frente a un 0,2\% de decorticado primario y un $0,8 \%$ de secundario, lo que redunda en nuestra idea de que las labores de desbastado eran realizadas al exterior, en la cercana terraza. Los formatos, en el caso de las cuarcitas, siguen las pautas observadas en los niveles inferiores con predominio de tamaños pequeños y medianos, aunque en este nivel se documenta una interesante colección en un formato más grande, colección a la que se suman algunas hojas, mucho menos representadas $(0,1 \%)$ aunque de idéntico tamaño. Sigue siendo muy notable la proporción de hojitas (9\%), todas caracterizadas como simples.

En lo referido a los materiales empleados continúa la preponderancia del sílex $(60,4 \%)$, aunque las cuarcitas experimentan un notable aumento $(37,9 \%)$ y los cuarzos, dentro de una presencia siempre muy limitada, también se observan en mayor cantidad; un 1,6\% frente al 0,4\% registrado en el nivel VII o el 0,2\% del nivel VIII.

La industria ósea, no documentada en los niveles inferiores, se encuentra profusamente representada en éste (Tab. 3), desde su parte basal hasta el techo, con un registro total de 88 piezas. De entre ellas destaca ampliamente el grupo de las azagayas con un 59,09\%, presentando secciones ovaladas y cilíndricas, algunas decoradas con trazos grabados en "V" invertida en la zona proximal acuñada para facilitar el enmangue; le siguen en frecuencia el grupo de los tensores con un $17,05 \%$ y los punzones, tanto de sección cilíndrica como triangular, con un $15,91 \%$ y, ya más escasas, las agujas con un 4,55\%. Finaliza este registro industrial óseo con 2 espátulas, una de las cuales se encuentra decorada con grabados lineales y la silueta de un cérvido (Figura 6), y 1 fragmento de propulsor correspondiente a la zona de apoyo de la azagaya.

La fauna (Tab. 4), con un total de 1.385 restos reconocibles, continúa estando representada básicamente por las mismas especies, Capreolus capreolus (0,07\%), Equus ferus $(1,23 \%)$, Capra pyrenaica $(7,73 \%)$, Rupicapra rupicapra $(37,69 \%)$ y Cervus elaphus $(53,29 \%)$, aunque experimentando algunas variaciones en su proporción respecto a los niveles inferiores.

\subsection{Estrato V}

Por último, nos referiremos al nivel $V$ que se encuadra en los primeros momentos del Cantábrico II (Lascaux) y que constituye un fuerte nivel de limos de inundación, estériles arqueológicamente, que penetra hasta el fondo de la cueva. En primer lugar, es el responsable directo en los momentos iniciales de su formación del fuerte lavado en superficie del 


\begin{tabular}{|c|c|c|c|c|c|}
\hline & \multirow{2}{*}{ Secuencia sedimentoclimática } & \multicolumn{4}{|c|}{ Cantábrico I (Dryas antiguo) } \\
\hline & & Fase 3 & & & Fase 1 \\
\hline \multirow{2}{*}{\multicolumn{2}{|c|}{ Secuencia cultural }} & \multicolumn{4}{|c|}{ Solutrense } \\
\hline & & \multicolumn{2}{|c|}{ superior } & medio final & medio \\
\hline & Estrato & VI & VII & VIII & IXa (Techo) \\
\hline \multirow{9}{*}{ 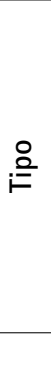 } & Protoarpón & 0 & 0 & 0 & 0 \\
\hline & Arpón & 0 & 0 & 0 & 0 \\
\hline & Azagaya & 52 & 0 & 0 & 0 \\
\hline & Aguja & 4 & 0 & 0 & 0 \\
\hline & \begin{tabular}{|l|} 
Punzón \\
\end{tabular} & 14 & 0 & 0 & 0 \\
\hline & Propulsor & 1 & 0 & 0 & 0 \\
\hline & Espátula & 2 & 0 & 0 & 0 \\
\hline & Tensor & 15 & 0 & 0 & 0 \\
\hline & Total de Registros & 88 & 0 & 0 & 0 \\
\hline
\end{tabular}

ه TABla 3. Utillaje óseo de los niveles solutrenses de la galería oriental o de la excavación de la cueva de La Lluera I.

\begin{tabular}{|c|c|c|c|c|c|}
\hline & \multirow{2}{*}{ Secuencia sedimentoclimática } & \multicolumn{4}{|c|}{ Cantábrico I (Dryas antiguo) } \\
\hline & & Fase 3 & Fase 2 & & \\
\hline \multirow{2}{*}{\multicolumn{2}{|c|}{ Secuencia cultural }} & \multicolumn{4}{|c|}{ Solutrense } \\
\hline & & \multicolumn{2}{|c|}{ superior } & medio final & medio \\
\hline & Estrato & VI & VII & VIII & IXa (Techo) \\
\hline \multirow{6}{*}{$\begin{array}{l}\frac{\mathscr{\nu}}{\tilde{u}} \\
\frac{\tilde{\nu}}{\tilde{n}}\end{array}$} & Ciervo (Cervus elaphus) & 738 & 168 & 103 & 0 \\
\hline & Rebeco (Rupicapra rupicapra) & 522 & 103 & 47 & 0 \\
\hline & Cabra (Capra pyrenaica) & 107 & 73 & 14 & 0 \\
\hline & Caballo (Equus ferus) & 17 & 8 & 2 & 0 \\
\hline & Uro (Bos primigenius) & 0 & 1 & 0 & 0 \\
\hline & Corzo (Capreolus capreolus) & 1 & 0 & 0 & 0 \\
\hline & Total de Registros & 1.385 & 353 & 166 & 0 \\
\hline
\end{tabular}

TABLa 4. Macrofauna de los niveles solutrenses de la galería oriental o de la excavación de la cueva de La Lluera I (Según Altuna 1994a).

techo del nivel VI que motivó que se perdieran, como ya hemos apuntado, gran parte de los registros del momento Solutrense superior final; aunque podemos, con las necesarias matizaciones y prudencia, citar su presencia basándonos en el registro industrial documentado a techo y en las variaciones observadas en el sedimento (Hoyos 1994, 1995). En segundo lugar, su formación constituyó un afortunado sello para la serie solutrense de La Lluera I, separándola nítidamente de los momentos culturales posteriores a partir del cuadro $\mathrm{H}-8$ y preservándola integramente en los cuadros H-9, G-10, H-10 y gran parte de G-11 y H-11, que quedaron así protegidos bajo su potente capa de limos de las posteriores inundaciones del río.

\section{CONCLUSIONES}

En definitiva, durante todo el Tardiglaciar la cueva de La Lluera I ha estado sometida a un fuerte sistema de inunda- ciones y vaciados de la cavidad que ha modelado la estratigrafía antrópica de una manera muy importante, llegando, a veces, a hacer desaparecer niveles, a minimizarlos o a mezclarlos en alguna medida. Por ello, su estratigrafia ha de interpretarse desde el análisis sedimentológico y morfológico del río Nalón (Hoyos 1994, 1995), a cuya actividad han de unirse, también, las aguas provenientes de la surgencia de desagüe de la ladera en cuya base se localiza la cavidad y que desde cuyo interior arrastra hacia el exterior los materiales depositados en ella.

Presentamos en este trabajo los niveles inferiores de la serie estratigráfica de la Galeria oriental o de la excavación de la cueva de La Lluera I que abarcan una horquilla cultural que va del Solutrense medio al Solutrense superior terminal, registrándose así mismo el Solutrense medio final y el superior, que se constituye como el momento de máxima intensidad en la ocupación de esta cultura en la cueva. Serie industrial que se inscribe dentro de los parámetros tecnotipológicos y materiales reconocidos para el Solutrense cantá- 
brico (Rasilla 1994) y que se enmarca sedimentológicamente entre los momentos finales del Würm III-IV (Laugerie) en que tras el desmantelamiento de la terraza de $+5 \mathrm{~m}$, lo cual también se constata en la base estratigráfica de la cueva de La Lluera II (Rodríguez Asensio 1992; Rodríguez Asensio et al. 2012; Hoyos 1994, 1995), la cueva comienza a registrar ocupaciones antrópicas y los inicios del Cantábrico II (Lascaux) en que los niveles solutrenses quedan sellados por los aportes fluviales estériles del Estrato V. Esto es, una serie cultural que se verifica durante el Cantábrico I (Dryas antiguo) coincidiendo en su desarrollo con las fases húmeda fría, menos húmeda de frío intenso y húmeda fría definidas por Hoyos (1994, 1995). Variaciones climáticas que también pueden observarse en el registro macrofaunístico (Altuna 1994b, 1995, 2002; Yravedra 2002) en el que el ciervo (Cervus elaphus) cede su papel predominante, $62,1 \%$ frente a un $8,4 \%$ de cabra (Capra pyrenaica) y un $28,3 \%$ de rebeco $(R u-$ picapra rupicapra) entre la fauna cazada registrada durante la primera fase húmeda fría del Cantábrico I, en beneficio de la cabra (Capra pyrenaica) y el rebeco (Rupicapra rupicapra) que alcanzan un $20,7 \%$ y un $29,2 \%$ respectivamente frente a un $47,5 \%$ de ciervo (Cervus elaphus) durante la segunda fase menos húmeda de frío intenso, para volver a recuperar ligeramente su predominancia, un 53,3\% de ciervo (Cervus elaphus) frente a un $37,7 \%$ de rebeco (Rupicapra rupicapra) especie que continúa su progresivo aumento en las preferencias de caza y un 7,7\% de cabra (Capra pyrenaica) en marcado retroceso ya durante la fase húmeda fría final.

La dinámica de las ocupaciones antrópicas documentadas en la cueva para este registro Solutrense viene expresada por un momento inicial, que inscribimos dentro del Solutrense medio por afinidad sedimentológica con la cueva de Las Caldas (Hoyos 1994, 1995), justo en el momento en que se verifica el desmantelamiento de la terraza $+5 \mathrm{~m}$ y la cueva se ve libre de los sedimentos de ésta, nivel $X$, que la taponaban, durante el final del Würm III/IV (Laugerie). Es una primera ocupación exigua y puntual que apenas deja huella; descartando, en este sentido, encontrarnos ante los restos del registro de una ocupación más intensa que fue arrasada por las inundaciones posteriores, por la circunstancia de que la industria conserva elementos tanto de mediano (restos de núcleo) como de pequeño formato (lascas y hojitas), que lógicamente habrian de ser los primeros en ser arrastrados, con las aristas frescas y sin signo alguno de desgastes por rodado. Tras ella da comienzo un largo ciclo de intrusiones sucesivas que da lugar a una gruesa secuencia de limos de inundación que formarán el nivel IXa. Durante ese proceso y en un momento no intrusivo, casi a techo del nivel, se verifica una segunda ocupación antrópica de idénticas características culturales y de duración en el tiempo que la anterior. Este ciclo se desarrollará durante gran parte de la primera fase del Cantábrico I cambiando radicalmente en los momentos finales de ésta, en que el ciclo de transgresiones del río da paso a otro en el que la sedimentación obedece ya a procesos de gelivación, aportes detríticos del interior de la cueva y antrópicos, con una duración que abarcará todo el resto del Cantábrico I (Dryas antiguo) hasta su final (Hoyos 1994, 1995).

Será durante este segundo ciclo cuando las ocupaciones antrópicas vayan desarrollándose de una forma más nítida y gradualmente intensa. Así, durante los momentos finales de la primera fase del Cantábrico I se asiste a la formación del nivel VIII, en el que se registran industrias que inscribimos en el Solutrense medio final, acompañadas de restos faunísticos con marcas de descarnado, claro indicador de la cueva como asentamiento. No obstante se trata de una muestra bastante reducida que nos hace interpretar esta ocupación como de baja intensidad, probablemente como refugio ocasional durante las partidas de caza o de breve parada durante los desplazamientos de los grupos humanos. Esta misma interpretación podemos extrapolarla sin otras salvedades al siguiente nivel, VII, aunque matizando un uso de mayor intensidad ante la evidencia del notable aumento del registro conservado; ocupaciones estas que ya inscribimos dentro del Solutrense superior. $Y$ así podríamos seguir interpretando la presencia humana en esta cueva en lo que respecta al nivel VI subsiguiente, con clara continuación cultural dentro del Solutrense superior y un posible Solutrense superior final a techo. Sin embargo, en este nivel VI se verifican circunstancias que rarifican esta interpretación continuista del uso y nos empujan, sin descartarla completamente como una de las posibles, a formular otras que con todas las prudencias se presentan como más acertadas.

Hemos de recordar aquí que uno de los principales objetivos fijados dentro del "Proyecto Nalón medio" para la excavación arqueológica de la cueva era la de encontrar la posible conexión entre el excepcional arte desarrollado en los paneles grabados de la Galería occidental y los suelos de ocupación humana. Dicho esto, hemos de observar la absoluta imposibilidad de que tales grabados sean anteriores al final del Würm III/IV (Laugerie), momento en que, como muestra la serie estratigráfica, se produce el desmantelamiento de la terraza $+5 \mathrm{~m}$ y por tanto el destaponamiento de la oquedad que marca el terminus post quem del hecho artístico, del mismo modo que el nivel $\mathrm{V}$ marcará su terminus ante quem, ya que el siguiente momento de ocupación nos Ilevaría hasta los tiempos del Magdaleniense superior, verificado en este yacimiento durante el Cantábrico VII. Con ello queda de manifiesto que la realización de los grabados ha de incluirse necesariamente dentro del citado paréntesis temporal. Ahora bien, ¿podemos interpretar como refugio o parada ocasional de un grupo nómada un lugar dotado de la exuberancia artística presente en La Lluera I, o hemos de buscar otras interpretaciones?

Evidentemente nos ratificamos en la primera interpretación para explicar los niveles Xla, VIII y VII, sin descartar 
que durante estas ocupaciones pudieran haberse realizado algunos de los grabados y por tanto que no nos encontremos ante un único horizonte artístico. Hemos de notar, llegados a este punto, que los estudios sobre el arte desarrollado en la Galería occidental de esta cueva se centraron y continúan centrándose obstinadamente en los paneles donde las figuras son marcadamente visibles y de relativamente fácil lectura, como es el caso del caballo del panel de entrada, de las representaciones de ciervas, uros y caballos presentes en la llamada gran hornacina o de algunas otras pocas figuras zoomorfas aisladas, quedando siempre de lado en estos estudios los complejísimos grabados que, en laberíntica composición, conforman los grandes paneles que tatúan las paredes izquierda y derecha de entrada a la galería norte y que constituyen la verdadera singularidad artística de esta cueva. Un abigarrado universo abstracto de trazos superpuestos, marcadamente profundos, y dispuestos en una especie de huida al horror vacui, donde apenas puede distinguirse con dificultad algunas figuras zoomorfas y unos pocos signos. Universo que precisó para su realización de una ocupación intensa y duradera en el tiempo, y que ahora podemos emparejar con la ocupación registrada arqueológicamente durante el proceso que conformó el nivel VI. Esto es, durante la tercera fase del Cantábrico I.

Esta correlación grabados/momentos de ocupación del nivel VI, marcaría ya por sí misma la interpretación que hemos de plantear para el uso antrópico de la cueva durante este periodo, pues difícilmente podemos hacerla encajar en su explicación como refugio fugaz o lugar de parada ocasional. También debemos descartar aquí su posible uso como lugar de habitación permanente, al menos como lugar de habitación de un grupo humano de mediana o gran entidad, debido a lo reducido de sus dimensiones que apenas dan cabida a una decena de personas. Con ello la interpretación más plausible teniendo en cuenta estos aspectos, a los que tenemos que sumar su ubicación centrada respecto al resto de yacimientos paleolíticos de la cuenca media del Nalón, sería la de santuario al que se desplazarían los grupos o, mejor, algunos miembros de estos grupos de un modo frecuente a formalizar aspectos que obviamente habrán de estar intimamente relacionados con sus costumbres, ritos o creencias.

\section{BIBLIOGRAFÍA}

ALtunA, J. 1994a: "La relación fauna consumida - fauna representada en el Paleolítico superior cantábrico". Complutum 5: 303-311.

- 1994b: "Los Macromamíferos durante el Solutrense de la Península Ibérica". Férvedes 1: 47-56.

- 1995: "Faunas de mamíferos y cambios ambientales durante el Tardiglaciar". En A. Moure Romanillo y C. González Sainz (coords.): El final del Paleolítico cantábrico: transformaciones ambientales y culturales durante el Tardiglacial y comienzos del Holoceno en la Región Cantábrica. Servicio de Publicaciones de la Universidad de Cantabria. Santander: 77-118.

- 2002: "Los animales representados en el arte rupestre de la Península Ibérica. Frecuencias de los mismos". Munibe 54: 21-33.

Corchón Rodríguez, M. S. 1999: "Solutrense y Magdaleniense del oeste de la Cornisa Cantábrica: Dataciones 14C (calibradas) y marco cronológico". Zephyrvs LII: 3-32.

- 1981: Cueva de Las Caldas. San Juan de Priorio (Oviedo). Excavaciones Arqueológicas en España 115. Ministerio de Cultura. Madrid.

- 1990: "La Cueva de Las Caldas (Priorio, Oviedo). Investigaciones efectuadas entre 1980 y 1986". Excavaciones Arqueológicas en Asturias 1983-1986. Servicio de Publicaciones del Principado de Asturias. Oviedo: 37-53.

Fortea Pérez, F. J. 1981: "Investigaciones en la cuenca media del Nalón. Asturias (España). Noticia y primeros resultados". Zephyrvs XXXIIXXXIII: 5-16.

- 1989: "Cuevas de La Lluera. Avance al estudio de sus artes parietales". En M. R. González Morales (coord.): Cien años después de Sautuola: Estudios en homenaje a Marcelino Sanz de Sautuola en el Centenario de su muerte. Diputación Regional de Cantabria. Santander: 187-202.

- 1990a: "Proyecto de investigación integrada Nalón medio". Excavaciones Arqueológicas en Asturias 1983-1986. Servicio de Publicaciones del Principado de Asturias. Oviedo: 13.

- 1990b: "Cuevas de La Lluera. Informe sobre los trabajos referentes a sus artes parietales". Excavaciones Arqueológicas en Asturias
1983-1986. Servicio de Publicaciones del Principado de Asturias. Oviedo: $19-28$.

- 1994: "Los "santuarios" exteriores en el Paleolítico cantábrico". Complutum 5: 203-220.

- 2001: "Los comienzos del Arte paleolítico en Asturias: Aportaciones desde una arqueología contextual no postestilistica". Zephyrvs LIIILIV: $177-216$.

- 2005: "Iberian palaeolithic rock art". Coalition 10: 8-14.

Garcia, N. y ARSUAGA, J. L. 2003: "Last Glaciation cold-adapted faunas in the Iberian Peninsula". En J. W. F. Reumer, J. De Vos y D. Mol (eds.): Advances in mammoth research (Proceedings of the Second International Mammoth Conference, Rotterdam, May 16-20 1999). Deinsea 9: 159-169.

GonzÁlez Echegaray, J. y GonzÁlez Sáinz, C. 1994: "Conjuntos rupestres paleolíticos de la Cornisa Cantábrica". Complutum 5: 21-43.

GonzÁlez SÁinz, C. 2000: "Representaciones arcaicas de bisonte en la Región Cantábrica". Spal 9: 257-278.

- 2004: "Arte parietal en la Región Cantábrica: Centros y peculiaridades regionales". Kobie 8: 403-424.

Hernando Álvarez, C. 2011a: "Nuevas perspectivas de un viejo problema: los grabados exteriores premagdalenienses de la Cornisa Cantábrica. Contexto cronológico y homogeneidad gráfica". Munibe 62: 101-116.

- 2011b: "La aplicación del modelo morfotipológico en los grabados exteriores del Paleolítico cantábrico". Estrat Crític 5 (1): 32-41.

Hoyos, M. 1989: "La Cornisa Cantábrica". En A. Pérez-González, P. Cabra y A. Martín-Serrano (eds.): Mapa del Cuaternario de España. ITGE. Madrid: 105-119.

- 1994: "Caracteristicas Sedimentokársticas de los Interestadios Laugerie y Lascaux en la Cornisa Cantábrica". Férvedes 1: 21-37.

- 1995: "Paleoclimatología del Tardiglaciar en la Cornisa Cantábrica basada en los resultados sedimentológicos de los yacimientos arqueológicos kársticos". En A. Moure Romanillo y C. González Sainz (coords.): El final del paleolítico cantábrico: transformaciones ambientales y culturales durante el Tardiglacial y comienzos del Holoceno en la Región Cantábrica. Servicio de Publicaciones de la Universidad de Cantabria. Santander: 77-117. 
Montes Barquín, R., Muñoz Fernández, E. y Morlote Expósito, J. M. 2002: "Los grabados rupestres paleolíticos de la cueva de La Luz (Ramales de La Victoria, Cantabria)". Nivel Cero 10: 23-32.

Moure RomanilLo, A. 1994: "Arte paleolítico y geografias sociales. Asentamiento, movilidad y agregación en el final del Paleolítico cantábrico". Complutum 5: 313-330

RASILLA VIVES, M. DE LA 1994: "El Solutrense de la Cornisa Cantábrica". Férvedes 1: 69-87

Rodriguez AsensIO, J. A. 1990: "Excavaciones arqueológicas realizadas en la cueva de La Lluera (San Juan de Priorio. Oviedo)". Excavaciones Arqueológicas en Asturias 1983-1986. Servicio de Publicaciones del Principado de Asturias, Oviedo: 15-17.

- 1992: "Excavaciones arqueológicas en la cueva de La Lluera II (San Juan de Priorio. Oviedo)". Excavaciones Arqueológicas en Asturias 1987-1990. Servicio de Publicaciones del Principado de Asturias, Oviedo: 29-32.

Rodriguez Asensio, J. A., Barrera Logares, J. M. y Aguilar Huergo, E. 2012: "Cueva de La Lluera II (San Juan de Priorio. Oviedo. Asturias. España): Estudio integral de un santuario complementario solutrense".
Libro de Resúmenes Congreso Internacional El Solutrense, VélezBlanco, Almería (España), 25 -28 junio 2012. Madrid: 121-122.

Rodriguez Asensio, J. A., González Morales, M. R., Dupré Olitiver, M., Corchón Rodriguez, M. S., Hoyos Gómez, M., Laville, H., Fortea Pérez, F. J. y Fernández-Tresguerres Velasco, J. A. 1989: "Neue Untersuchungen in den Flusstalern des Nalon und des Sella (Asturien)". Madrider Mitteilungen 30: 1-30.

Rodriguez Asensio, J. A., Fortea, F. J., Corchón, M. S., GonzÁlez Morales, M., Hoyos, M., Laville, H., Dupre, M. y Fernández-Tresguerres, J. 1990: "Travaux récents dans les vallées du Nalon et du Sella (Asturies)". L'Art des objets au Paleolithique 1: L' Art Mobilier et son Contexte. Colloque International, Foix-Le Mas d' Azil, novembre 1987. Actes des Colloques de la Direction du Patrimoine. Paris: 219-244.

Ruiz ReDondo, A. 2011: "Convenciones gráficas en el arte parietal del Paleolítico cantábrico: La perspectiva de las figuras zoomorfas". Trabajos de Prehistoria 68 (2): 259-274

Yravedra Sálnz de los Terreros, J. 2002: "Especialización o Diversificación. Una nueva propuesta para el Solutrense y el Magdaleniense Cantábrico". Munibe 54: 3-20. 